\title{
Coupling of fog and marine microbial content in the near-shore coastal environment
}

\author{
M. E. Dueker ${ }^{1}$, G. D. O'Mullan ${ }^{1,2}$, K. C. Weathers ${ }^{3}$, A. R. Juhl ${ }^{1}$, and M. Uriarte ${ }^{4}$ \\ ${ }^{1}$ Lamont Doherty Earth Observatory, Columbia University, 61 Route 9W, Palisades, NY 10964, USA \\ ${ }^{2}$ School of Earth and Environmental Sciences, Queens College, City University of New York, 65-30 Kissena Blvd., \\ Flushing, NY 11367, USA \\ ${ }^{3}$ Cary Institute of Ecosystem Studies, Box AB, Millbrook, NY 12545-0129, USA \\ ${ }^{4}$ Ecology, Evolution, and Environmental Biology Department, Columbia University, 2960 Broadway, New York, NY \\ 10027-6902, USA
}

Correspondence to: M. E. Dueker (med2109@ columbia.edu)

Received: 1 September 2011 - Published in Biogeosciences Discuss.: 23 September 2011

Revised: 19 December 2011 - Accepted: 31 January 2012 - Published: 17 February 2012

\begin{abstract}
Microbes in the atmosphere (microbial aerosols) play an important role in climate and provide an ecological and biogeochemical connection between oceanic, atmospheric, and terrestrial environments. However, the sources and environmental factors controlling the concentration, diversity, transport, and viability of microbial aerosols are poorly understood. This study examined culturable microbial aerosols from a coastal environment in Maine (USA) and determined the effect of onshore wind speed and fog presence on deposition rate, source, and community composition. During fog events with low onshore winds $\left(<2 \mathrm{~m} \mathrm{~s}^{-1}\right)$ the near-shore deposition of microbial aerosols (microbial fallout) decreased with increasing wind speeds, whereas microbial fallout rates under clear conditions and comparable low wind speeds showed no wind speed dependence. Mean aerosol particle size also increased with onshore wind speed when fog was present, indicating increased shoreward transport of larger aerosol particles. 16S rRNA sequencing of culturable ocean surface bacteria and microbial aerosols deposited onshore resulted in the detection of 31 bacterial genera, with 5 dominant genera (Vibrio, Bacillus, Pseudoalteromonas, Psychrobacter, Salinibacterium) making up $66 \%$ of all sequences. The sequence library from microbial aerosol isolates, as with libraries found in other coastal/marine aerosol studies, was dominated at the phylum level by Proteobacteria, with additional representation from Firmicutes, Actinobacteria and Bacteroidetes. Seventy-five percent of the culturable microbial aerosols falling out under foggy conditions were most similar to GenBank-published sequences detected in marine environments. Using a $97 \%$ similarity cut-off, sequence libraries from ocean surface
\end{abstract}

and fog isolates shared eight operational taxonomic units (OTU's) in total, three of which were the most dominant OTU's in the library, representing large fractions of the ocean $(28 \%)$ and fog $(21 \%)$ libraries. The fog and ocean surface libraries were significantly more similar in microbial community composition than clear (non-foggy) and ocean surface libraries, according to both Jaccard and Sorenson indices. These findings provide the first evidence of a difference in community composition and microbial culturability of aerosols associated with fog compared to clear conditions. The data support a dual role for fog in enhancing the fallout of viable microbial aerosols via increased gravitational settling rates and decreased aerosolization stress on the organisms, which may include relief from UV inactivation, desiccation, and oligotrophic microconditions. This study provides a strong case for ocean to terrestrial transport of microbes and a potential connection between water quality and air quality at coastal sites.

\section{Introduction}

Current global estimates of bacterial concentrations in the atmosphere (microbial aerosols) range from $1 \times 10^{4}$ to $6 \times 10^{5}$ cells $\mathrm{m}^{-3}$ depending on ecosystem type (Shaffer and Lighthart, 1997; Bauer et al., 2002; Burrows et al., 2009). Despite the existence of this ubiquitous microbial reservoir, the sources maintaining this microbiome remain understudied, as do the environmental factors that control the abundance, viability, diversity, and deposition dynamics of microbial aerosols. Aerosolized bacteria can reproduce under 
controlled laboratory conditions (Dimmick et al., 1979a, b) and have the metabolic potential to biogeochemically mediate atmospheric chemistry (Ariya et al., 2002; Amato et al., 2005; Vaitilingom et al., 2011). There is also growing evidence that microbial aerosols impact climate by serving as fog, cloud, and ice nucleators (Posfai et al., 1995; Hamilton and Lenton, 1998; Bauer et al., 2003; Ariya et al., 2009; Ekstrom et al., 2010). Finally, the atmospheric transport of microbes between ecosystem types, such as from African desert soils to the Caribbean Sea (Prospero et al., 2005), or from ocean surface to land in coastal systems (Dueker et al., 2011), has important implications for our understanding of microbial biogeography and genetic exchange among seemingly isolated microbiomes.

Within the context of biogeochemical fluxes from ocean to land, aerosols provide a mechanism for transfer of microbes, nutrients, and pollutants. Marine particulates (including marine microbes) are known to enrich ambient aerosols in the air layer above marine waters (Kuznetsova et al., 2004; Aller et al., 2005; Seinfeld, 2006), and are delivered inland at coastal sites during onshore winds (Vignati et al., 1999; de Leeuw et al., 2000; Dueker et al., 2011). Three mechanisms dominate the supply of marine particulates to the atmosphere: bubble eruption (Woodcock, 1953; Blanchard and Syzdek, 1971; Marks et al., 2001), wind-wave interactions (Fitzgerald, 1991), and, at coastal sites, wave-shore interactions (de Leeuw et al., 2000; Dueker et al., 2011). The contribution of these supply mechanisms to the community composition and transport of coastal microbial aerosols has rarely been studied.

Even less is known about the environmental factors that enable microbes to persist in the atmosphere after aerosolization in the near-shore environment. UV exposure, desiccation, temperature shock, $\mathrm{pH}$ reduction and oligotrophic microconditions can inactivate marine microbes upon ejection from surface waters. Researchers have suggested a number of mechanisms that may foster persistence of aerosolized microbes, including carotenoid pigmentation (Amato et al., 2005), high humidity (Griffiths and Decosemo, 1994), association with larger gel-like particles formed from marine organic matter (Aller et al., 2005), and incorporation into fog or cloud droplets (Fuzzi et al., 1997; Deguillaume et al., 2008). Fog may be particularly important to microbial aerosol viability in coastal environments given its frequent occurrence at many temperate coastal sites (Weathers et al., 1988; Weathers, 1999; Weathers et al., 2000; Dueker et al., 2011). Despite the fact that fog greatly increases the deposition of culturable microbes and fungi (Fuzzi et al., 1997; Dueker et al., 2011), and pathogenic viral particles (Castello et al., 1995), a molecular analysis of viable microbes in fog water has never before been reported. The effects of fog on microbial aerosol viability also remain unknown.

This study uses field and molecular data to address some of the fundamental gaps in current knowledge about sources of microbial aerosols in coastal environments and the en- vironmental factors that influence their viability. First, we examined the impact of fog and onshore winds on culturable microbial fallout rates and microbial community composition. Coastal fog can increase viable microbial fallout via two mechanisms: increased gravitational settling rate, through the condensation of water on existing particles during fog formation, and enhanced microbial viability, through relief from aerosolization stressors including UV inactivation, desiccation, and oligotrophic microconditions (Fuzzi et al., 1997; Dueker et al. 2011). In this study, we tested the potential importance of enhanced viability by comparing the community composition of culturable microbial aerosols under clear and foggy conditions. If fog enhances microbial viability, the culturable microbial aerosols falling out under clear conditions should be distinct from those falling out under foggy conditions. Specifically, the microbial fallout during clear (non-foggy) conditions would be expected to consist of microbes that are more resistant to desiccation, UV exposure, and other environmental stresses. We further predict that the presence of increased onshore winds during fog events will increase transport distances of larger aerosol particles, resulting in decreased microbial fallout rates and increased importance of marine microbes in microbial aerosols depositing near-shore. Second, we tested the prediction that local production from adjacent ocean surfaces is the primary source of viable microbial aerosols falling out nearshore (Dueker et al., 2011) via the aforementioned supply mechanisms by comparing microbial composition in coastal aerosols and ocean surface water under variable environmental conditions (changing onshore wind speeds and fog presence/absence). If ocean and aerosol microbial communities are linked through local production from the ocean surface, microbes depositing near-shore should be genetically most similar to organisms found in the marine environment.

\section{Materials and methods}

The study site was located on a south-facing shore of Southport Island, ME, USA (N43.80261 W69.66841). Sampling occurred 28 June-7 July 2008; 8 September-14 September 2008; and 28 June-4 August 2009. To measure oneminute temperature, wind speed, wind direction, and humidity, a Vantage Pro2 Plus Weather Station (Davis Instruments, Hayward, CA) was installed $5 \mathrm{~m}$ above ground level within $20 \mathrm{~m}$ of aerosol particle sampling. Wind direction was used to assess local origin of sampled aerosols (onshore $=$ marine, offshore $=$ terrestrial). Wind speed, temperature and humidity were used in the field to gauge the likelihood of fog formation. Field observations and time-lapse photography were used to track fog presence/absence.

Microbial aerosols are attached to aerosol particles in a range of sizes, which determine gravitational settling rates and transport distance. To discern influences of fog and wind speed on aerosol particle size distribution, we used a Met 
One 9012 Ambient Aerosol Particulate Profiler (Met One Instruments, Grants Pass, OR) installed at a height of $2 \mathrm{~m}$, within $9 \mathrm{~m}$ of the mean high waterline and $20 \mathrm{~m}$ of aerosol sampling. One-minute data in bins with boundaries of 0.3 , $0.5,0.7,1,2,3,5$, and $10 \mu \mathrm{m}$ diameter $\left(D_{\mathrm{p}}\right)$ (cut-off of $\sim 30 \mu \mathrm{m})$ were continuously logged.

The aerosolization process creates a mix of viable and non-viable (damaged/dead) bacteria in ambient aerosols. Whereas culture-independent methods sample both viable and non-viable cells, culture-based sampling methods measure only the cells with metabolic machinery intact upon deposition. This distinction is important in terms of understanding the potential for biogeochemical transformations and for issues related to pathogen ecology and public health. Because not all viable bacteria are capable of growth on every media type, the results from this method provide a relative measure of culturable, and therefore viable, microbial aerosol fallout. To measure the culturable microbial aerosol population falling out near-shore, we exposed replicate (24) petri dishes containing LB media (Luria Bertani Agar, Miller, Fisher Scientific) to clear and foggy conditions for 30 minutes during onshore wind (or no wind) events. LB media was chosen specifically because it contains intermediate $\mathrm{NaCl}$ content and has been used in previous studies to culture diverse microbial aerosols in both terrestrial and coastal areas (Lighthart and Shaffer, 1995; Shaffer and Lighthart, 1997; Tong and Lighthart, 1997). The plates were exposed within $20 \mathrm{~m}$ of the weather station and particle profiler on a platform 6-10 $\mathrm{m}$ from the mean high waterline and approximately $1 \mathrm{~m}$ a.s.l. All plate exposures reported in this study were conducted when wind speeds were onshore and below $2 \mathrm{~m} \mathrm{~s}^{-1}$.

Exposed plates were incubated at room temperature (17.7$20.3{ }^{\circ} \mathrm{C}$ ), and bacterial colony forming units (CFU) were characterized for pigmentation and counted on the 8th day. Pearson's Chi-squared test was used to assess significant differences in pigmentation between ocean surface and aerosol colonies. Fungal colonies were observed but not included in the CFU count, and plates with fungal overgrowth were removed from analysis. Using number of CFU, duration of plate exposure, and area of agar exposed, microbial fallout rate $\left(\mathrm{cfu} \mathrm{m}^{-2} \mathrm{~s}^{-1}\right)$ was calculated and compared to onshore wind speeds. To assess culturability of ocean surface bacteria at the site, near-shore surface water $(<1 \mathrm{~m}$ depth) was collected during the first field season (2008), and $100 \mu \mathrm{l}$ was immediately spread on triplicate LB agar plates using sterile technique. These plates were incubated and enumerated under the same conditions described above for aerosol exposures. After enumeration, all media plates were stored at $4{ }^{\circ} \mathrm{C}$ until colonies were sampled for molecular analysis. Material picked from colonies was suspended in $50 \mu \mathrm{l}$ HyClone sterile water and boiled for 5 minutes to lyse the cells. This suspension was immediately frozen at $-20^{\circ} \mathrm{C}$ until PCR was performed.
To discern microbial aerosol community diversity and structure, 16S rRNA was amplified from picked colony suspensions using TopTaq DNA Polymerase (Qiagen, Valencia, CA) and universal bacterial primers $8 \mathrm{~F}$ $\left(5^{\prime}\right.$-AGRGTTTGATCCTGGCTCAG $\left.-3^{\prime}\right)$ and 1492R $\left(5^{\prime}\right.$ CGGCTACCTTGTTACGACTT-3') (Teske et al., 2002) with 35 PCR cycles of $45 \mathrm{~s}$ of denaturation at $94{ }^{\circ} \mathrm{C}, 45 \mathrm{~s}$ of annealing at $55^{\circ} \mathrm{C}$, and $1 \mathrm{~min}$ elongation at $72^{\circ} \mathrm{C}$. Agarose gel electrophoresis was conducted to confirm amplification of a single-sized DNA fragment, and to ensure that DNA-free controls did not yield amplification product. Single-read sequencing using the $8 \mathrm{~F}$ primer was performed on amplified PCR products by SeqWright Laboratories (Houston, TX). Sequences were quality-checked and edited using Geneious software (Drummond et al., 2010). Edited sequences yielding less than 350 base pairs of high quality sequence were removed from further downstream analyses. Remaining sequences (deposited in GenBank under accession numbers JQ657501 to JQ657701) were aligned using the Ribosomal Database Project (RDP) (Cole et al., 2009) and taxonomically classified using RDP's naive Bayesian rRNA classifier at an $80 \%$ confidence level (Wang et al., 2007). Using this classification, dominant genera from the library were identified as genera representing $5 \%$ or greater of the entire sequence library.

Sequence libraries from this study and other GenBankpublished aerosol studies (Amato et al., 2007; Fahlgren et al., 2010; Cho and Hwang, 2011; Urbano et al., 2011) were compared for significant differences in RDP's Library Compare Tool (using the naive Bayesian rRNA classifier (Wang et al., 2007)). To assess dominant source for culturable microbial aerosols from this study, each sequence was assigned one of four source categories (marine, terrestrial, marine + terrestrial, or aerosol) based on close matches with sequences reported in GenBank. Land animal and human sources were included in the terrestrial category, and ocean biota sources were included in the marine category. Closest matches (top hits) for all aerosol and ocean sequences were obtained using Geneious' Megablast function on the GenBank database. The sequence hit with the highest bit-score and the highest $\%$ Identical Sites value was designated the top hit for each sequence, and the reported sequence source was recorded. If more than one top hit was identified, the source for each top hit was recorded, and the source with the majority of hits was used to assign the sequence source category. Pearson's Chi-squared test was used to assess significant differences in categorical breakdowns between ocean surface and aerosol libraries. Unless otherwise specified, statistical analyses were performed using R statistical software (R Development Project 2008).

Jukes-Cantor corrected distance matrices constructed from aligned sequences in RDP were imported into the MOTHUR program (Schloss et al., 2009) to assign operational taxonomic units (OTU's) using the average neighbor algorithm at a $97 \%$ similarity cut-off. An OTU was considered dominant 


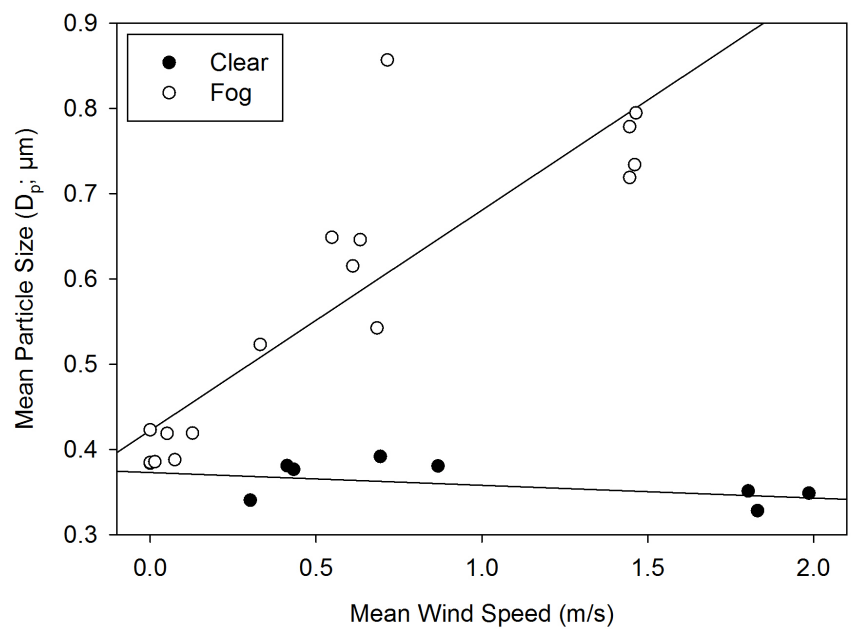

Fig. 1. Mean aerosol particle size $\left(D_{\mathrm{p}}, \mu \mathrm{m}\right)$ plotted against mean wind speed $\left(\mathrm{m} \mathrm{s}^{-1}\right)$ during microbial aerosol sampling events under clear and foggy conditions, coastal Maine, USA. Solid curves indicate linear regression models. Under foggy conditions, $R^{2}=0.77$ and $p<0.01$. Under clear conditions, $R^{2}=0.22$ and $p=0.14$.

if it represented $5 \%$ or more of the overall sequence library. Using the OTU analysis, Chao's Estimated Jaccard and Sorenson abundance-based similarity indices were calculated to evaluate similarities between the ocean sequence library and the clear and fog libraries. This method (performed in EstimateS (Colwell, 2009)) corrects commonlyused Jaccard and Sorenson indices with an estimated true value of shared species (appropriate for use with small data sets) and allows for a bootstrapping approach $(n=200)$ to generate $95 \%$ confidence intervals (C.I.'s) for the resulting test statistic (Chao et al., 2005).

\section{Results}

Meteorological conditions during plate exposures consisted of low wind speeds $\left(<2 \mathrm{~m} \mathrm{~s}^{-1}\right)$, high humidity, and frequent fog (Table 1). Fog presence and low wind speeds influenced mean aerosol particle size $\left(D_{\mathrm{p}}\right)$ (Fig. 1). Under clear conditions, mean particle size was not significantly related to wind speed $\left(R^{2}=0.22, p=0.137\right)$. However, with fog, mean particle size increased significantly with wind speed $\left(R^{2}=0.77\right.$, $p<0.01)$. During fog events, microbial aerosol fallout decreased as wind speeds increased (log-linear, $R^{2}=0.65$, $p<0.01$ ) (Fig. 2), whereas fallout rates under clear conditions showed no relationship to wind speed $\left(R^{2}=-0.03\right.$, $p=0.400$ ) under the low wind conditions examined in this study.

Overall, $86 \%$ of the culturable microbial aerosols were pigmented, and $76 \%$ of the culturable ocean bacteria were pigmented (significant difference, $p<0.01$ ). After colony picking, PCR amplification, sequencing, and quality control, a total of 164 aerosol 16S rRNA sequences (151 from foggy

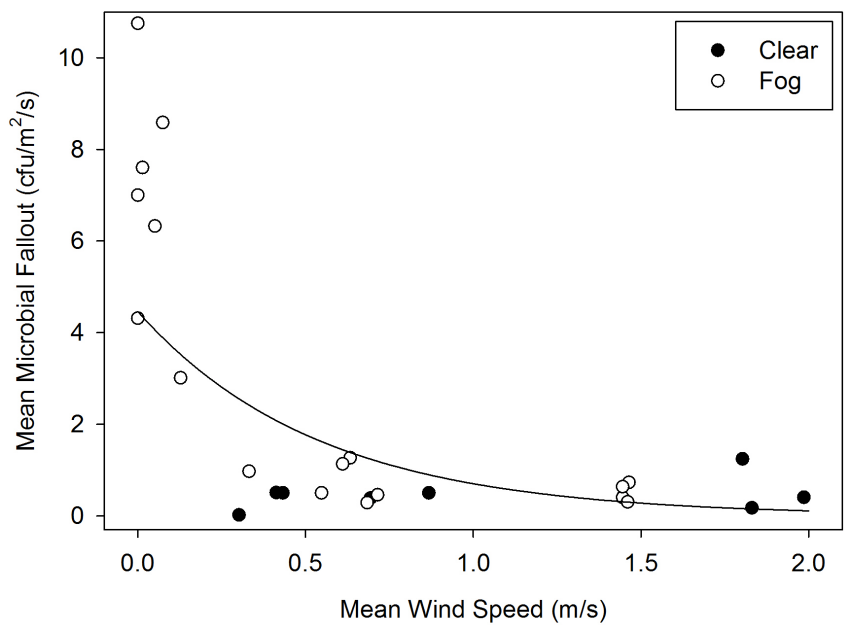

Fig. 2. Mean microbial fallout $\left(\mathrm{cfu} \mathrm{m}^{-2} \mathrm{~s}^{-1}\right)$ plotted against mean wind speed $\left(\mathrm{m} \mathrm{s}^{-1}\right)$ during microbial aerosol sampling events under clear and foggy conditions, coastal Maine, USA. The solid curve is based on regression of log-transformed data for fog events, $R^{2}=$ 0.65 and $p<0.01$.

conditions, 13 from clear conditions) and 37 ocean sequences were used in further analyses. Sequences were assigned to 31 total bacterial genera at $>80 \%$ confidence level, with 5 dominant genera (Vibrio, Bacillus, Pseudoalteromonas, Psychrobacter, Salinibacterium) representing $66 \%$ of the overall sequence library (Table 2). The microbial aerosol library, as well as sequence libraries from previously published coastal/marine aerosol studies, were analyzed for phylogenetic diversity and found to be diverse at the phylum level and dominated by Proteobacteria, with additional representation from Firmicutes, Actinobacteria and Bacteroidetes (Fig. 3). Within the Proteobacteria, Gammaproteobacteria dominated the microbial aerosol sequence library at this site (Fig. 4), and Vibrionales made up $37 \%$ of that class (and $21 \%$ of the total sequence library).

Source analysis of this study's sequences revealed that $75 \%$ of the viable microbial aerosols falling out under foggy conditions were most similar to sequences previously detected in marine environments (Fig. 5), which closely matched (and was not significantly different from $(p=0.58)$ ) the source analysis of coastal ocean surface sequences. In contrast, microbes falling out under clear conditions had only $54 \%$ marine closest hits (however, the difference between clear and foggy sources was not significant $(p=0.187))$ (Fig. 5). The remaining $46 \%$ of sequences from the clear condition library were most similar to GenBank sequences originating from terrestrial bacteria, including spore formers (Bacillus sp.), soil organisms (Burkholderia sp., Kocuria sp.) and other cosmopolitan bacteria (Serratia sp., Rhodococcus sp.). Sequences classified to the genera of Burkholderia, Kocuria, and Serratia were only found in the clear sequence library. 
Table 1. Meteorological context during microbial fallout sampling events (under foggy and clear conditions) from coastal Maine, USA.

\begin{tabular}{lccccc}
\hline & Conditions & Exposure Events & Humidity $(\mathrm{RH} \%)$ & Wind Speed $\left(\mathrm{m} \mathrm{s}^{-1}\right)$ & Temperature $\left({ }^{\circ} \mathrm{C}\right)$ \\
\hline 13 September 2008 & clear & 2 & $94.9 \pm 0.2$ & $0.62 \pm 0.11$ & $15.87 \pm 0.06$ \\
13 September 2008 & foggy & 4 & $96.9 \pm 0.2$ & $0.59 \pm 0.04$ & $14.93 \pm 0.07$ \\
16 July 2009 & clear & 5 & $89.8 \pm 0.2$ & $0.58 \pm 0.05$ & $18.76 \pm 0.08$ \\
17 July 2009 & foggy & 8 & $97.9 \pm 0.1$ & $0.03 \pm 0.01$ & $17.01 \pm 0.04$ \\
26 July 2009 & foggy & 5 & $98.8 \pm 0.1$ & $1.67 \pm 0.16$ & $17.82 \pm 0.05$ \\
2 August 2009 & foggy & 4 & $98.6 \pm 0.1$ & $1.29 \pm 0.11$ & $17.64 \pm 0.04$ \\
2 August 2009 & clear & 2 & $96.5 \pm 0.3$ & $1.89 \pm 0.03$ & $19.17 \pm 0.07$ \\
\hline
\end{tabular}

Table 2. Dominant ( $\geq 5 \%$ of total library) genera in this study's combined library (ocean surface + aerosols), coastal Maine, USA. OTU (\#) refers to the total number of OTU's found within that genus. OTU $(\%)$ is the percentage of the total OTU's $(n=76)$ found in the combined libraries. Seq (\#) is the number of total sequences assigned to that genus. Lib (\%) is the percentage of the entire sequence library assigned to that genus. Top Hits Source refers to the source most common among all sequences in that genus (terr. = terrestrial). An " $X$ " indicates the presence of this genus in the clear, fog, and/or ocean libraries.

\begin{tabular}{|c|c|c|c|c|c|c|c|c|c|c|}
\hline Phylum & Class & Genera & OTU (\#) & OTU $(\%)$ & Seq (\#) & $\operatorname{Lib}(\%)$ & Top Hits Source & Clear & Fog & Ocean \\
\hline Proteobacteria & Gammaproteobacteria & Vibrio & 11 & $14 \%$ & 39 & $19 \%$ & marine & $\mathrm{X}$ & $\mathrm{X}$ & $\mathrm{X}$ \\
\hline Proteobacteria & Gammaproteobacteria & Pseudoalteromonas & 5 & $7 \%$ & 30 & $15 \%$ & marine & & $\mathrm{X}$ & $\mathrm{X}$ \\
\hline Proteobacteria & Gammaproteobacteria & Psychrobacter & 4 & $5 \%$ & 23 & $11 \%$ & marine + terr. & & $\mathrm{X}$ & $\mathrm{X}$ \\
\hline Actinobacteria & Actinobacteria & Salinibacterium & 4 & $5 \%$ & 21 & $10 \%$ & marine & & $\mathrm{X}$ & \\
\hline \multirow[t]{2}{*}{ Firmicutes } & Bacilli & Bacillus & 6 & $8 \%$ & 20 & $10 \%$ & marine + terr. & $X$ & $X$ & $\mathrm{X}$ \\
\hline & & Total & 30 & $39 \%$ & 133 & $66 \%$ & & & & \\
\hline
\end{tabular}

Under foggy conditions, microbial aerosols depositing with no onshore winds $\left(<0.25 \mathrm{~m} \mathrm{~s}^{-1}\right)$ had higher fallout rates and were taxonomically different from those depositing with increased (although still relatively low $\left(<2 \mathrm{~m} \mathrm{~s}^{-1}\right)$ ) onshore winds (Fig. 2). The no-wind sequence library had significantly more Flavobacteria $(p<0.01)$, Psychrobacter sp. $(p<0.01)$, and Bacillus sp. $(p<0.01)$, than the wind library. The wind library consisted of a significantly larger proportion of Vibrio sp. $(p<0.01)$ than the no-wind sequence library.

OTU analysis of the total sequence library (fog, clear, and ocean combined) resulted in 76 OTU's (Supplement, Table 1), with 12 OTU's detected under clear conditions, 58 under foggy conditions, and 19 from the ocean surface (Fig. 6). GenBank accession numbers for sequences representing these OTU's are provided in the Supplement, Table 1. There were 6 dominant OTU's in this total sequence library, each shared between two or more of the fog, clear, and ocean surface sequence libraries. 2 OTU's (classified as Vibrio sp. and Bacillus sp.) were shared among all three libraries (Table 3). Fog and clear shared 3 additional OTU's, while clear and ocean shared no additional OTU's (Fig. 6). Fog and ocean shared 6 additional OTU's, including the 3 most dominant OTU's (Psychrobacter sp., Pseudoalteromonas sp. (2 OTU's)) which represented large fractions of the ocean $(28 \%)$ and fog $(21 \%)$ sequence libraries. Overall, $54 \%$ of the ocean sequence library was represented by OTU's shared with fog.
Five OTU's (classified as Psychrobacter sp., Pseudoalteromonas sp. (2 OTU's), Salinibacterium sp., and Vibrio sp.) dominated the fog sequence library, accounting for $36 \%$ of all fog sequences. The clear sequence library contained only 2 of these fog-dominant OTU's (Salinibacterium sp. and Vibrio sp.), representing $15 \%$ of the clear sequence library (Table 3). Both Chao-Jaccard and Chao-Sorenson indices calculated using the OTU analysis indicated that fog and ocean microbial communities were significantly more similar in structure than clear and ocean libraries (Table 4).

\section{Discussion}

\subsection{Local ocean surfaces are a dominant source of near-shore microbial aerosols.}

We found multiple lines of evidence, both physical and biological, supporting the prediction that local ocean surfaces serve as the dominant source of microbial aerosols in the near-shore coastal environment. First, the presence of increased (although still low) onshore winds during fog events at this site produced increased residence times for larger aerosol particles (which most likely originated from local sources given high settling rates of large particles), a simultaneous reduction in culturable microbial fallout, and a significant shift to marine organisms (specifically Vibrio sp.). Second, the majority of culturable microbial aerosol sequences 


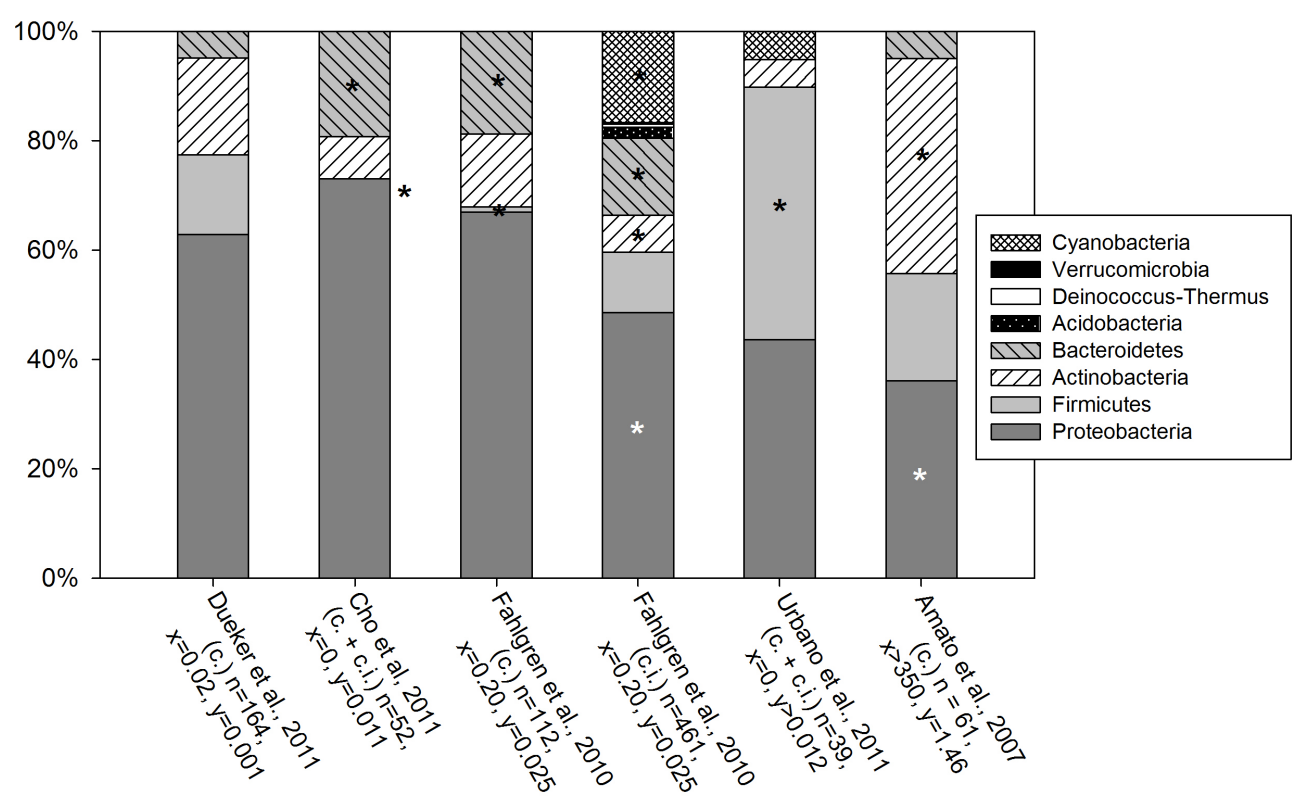

Fig. 3. Phylum-level classification of sequence libraries from this study's data (coastal Maine, USA) and GenBank-published sequence libraries from marine/coastal/cloud studies using culture-based (c.) and/or culture-independent (c.i.) methods. Number of sequences ( $n$ ), distance to shoreline $(\mathrm{km})(\mathrm{x})$, and sampling height $(\mathrm{km})(\mathrm{y})$ noted for each library. Classifications assigned using RDP's Naive Bayesian rRNA Classifier (80\% threshold) Version 2.2, March 2010. An asterisk (*) indicates significant differences in phylum-level community structure from this study as per RDP's Library Compare Tool, $p<0.01$. An asterisk outside a bar indicates that the library is significantly missing a phylum (asterisk placed at same height as this study's phylum breakdown).

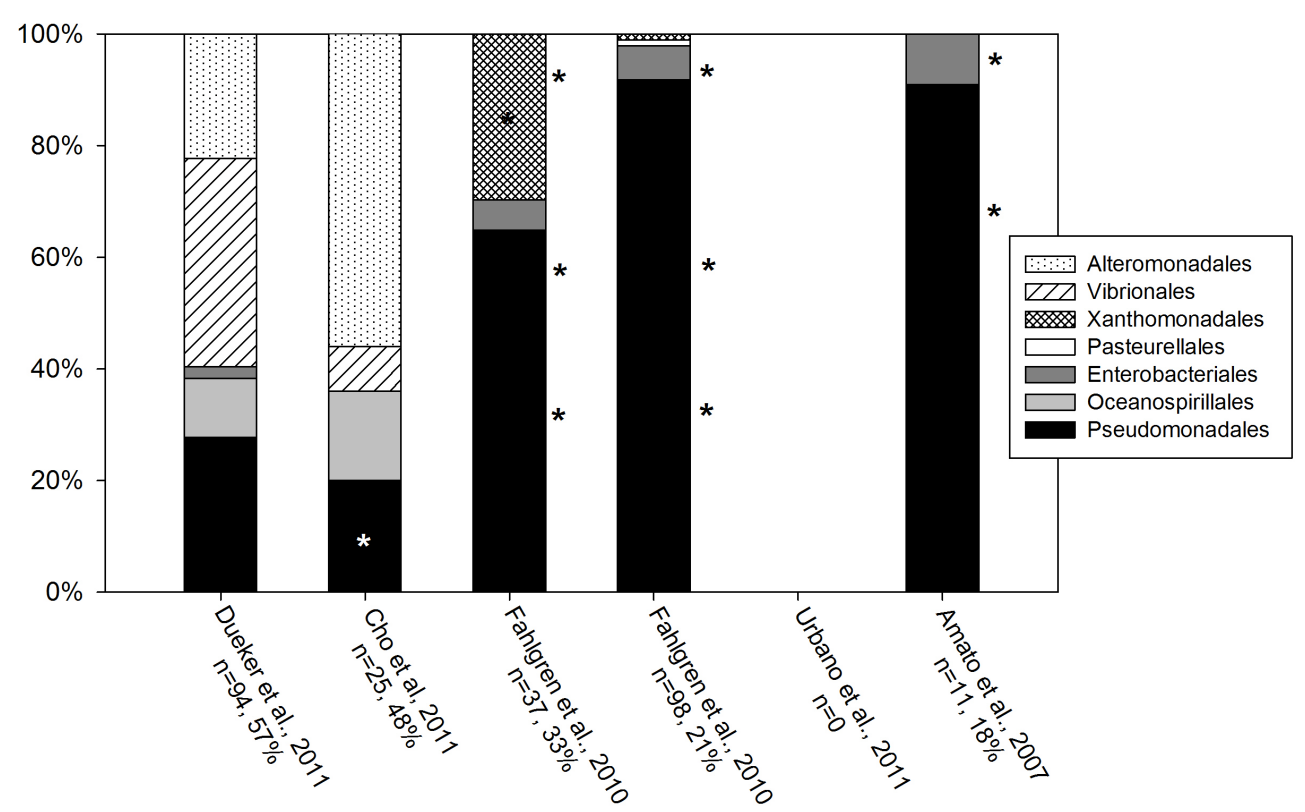

Fig. 4. Classification of Gammaproteobacteria presence in sequence libraries from our data (coastal Maine, USA) and GenBank-published data from marine/coastal/cloud studies from Fig. 3. Number of sequences $(n)$, and percent of total library that the Gammaproteobacteria accounted for noted. Classifications assigned using RDP's Naive Bayesian rRNA Classifier (80\% threshold) Version 2.2, March 2010. An asterisk $(*)$ indicates significant differences in phylum-level community structure from this study as per RDP's Library Compare Tool, $p<0.01$. An asterisk outside a bar indicates that the library is significantly missing an order (asterisk placed at same height as this study's order breakdown). 
Table 3. Details for OTU's shared between clear, fog, and ocean sequence libraries, coastal Maine, USA. OTU analysis from MOTHUR program using average neighbor and $97 \%$ similarity cut-off. Seq (\#) is the number of sequences represented by the OTU, Lib (\%) is the percent of overall sequence library represented by the OTU. Clear (\#), Fog (\#), Ocean (\#) refers to the number of sequences from each library represented by the OTU. Clear (\%), Fog (\%), Ocean (\%) refers to the percent of each sequence library represented by that OTU.

\begin{tabular}{|c|c|c|c|c|c|c|c|c|c|c|}
\hline Class & Genera & Seq (\#) & $\operatorname{Lib}(\%)$ & Top Hits Source & Clear (\#) & Clear $(\%)$ & Fog (\#) & Fog $(\%)$ & Ocean (\#) & Ocean $(\%)$ \\
\hline Gammaproteobacteria & Vibrio & 12 & $6 \%$ & marine & 1 & $8 \%$ & 9 & $6 \%$ & 2 & $5 \%$ \\
\hline Gammaproteobacteria & Pseudoalteromonas & 14 & $7 \%$ & marine & & & 6 & $4 \%$ & 8 & $22 \%$ \\
\hline Gammaproteobacteria & Cobetia & 6 & $3 \%$ & marine & 1 & $8 \%$ & 5 & $3 \%$ & & \\
\hline Gammaproteobacteria & Vibrio & 10 & $5 \%$ & marine & & & 5 & $3 \%$ & 5 & $14 \%$ \\
\hline Gammaproteobacteria & Psychrobacter & 15 & $7 \%$ & marine & & & 14 & $9 \%$ & 1 & $3 \%$ \\
\hline Gammaproteobacteria & Vibrio & 5 & $2 \%$ & marine & & & 4 & $3 \%$ & 1 & $3 \%$ \\
\hline Gammaproteobacteria & Pseudoalteromonas & 13 & $6 \%$ & marine & & & 12 & $8 \%$ & 1 & $3 \%$ \\
\hline Actinobacteria & Salinibacterium & 13 & $6 \%$ & marine & 1 & $8 \%$ & 12 & $8 \%$ & & \\
\hline Gammaproteobacteria & Listonella & 3 & $1 \%$ & marine & & & 2 & $1 \%$ & 1 & $3 \%$ \\
\hline Gammaproteobacteria & Cobetia & 2 & $1 \%$ & marine & 1 & $8 \%$ & 1 & $1 \%$ & & \\
\hline \multirow[t]{2}{*}{ Bacilli } & Bacillus & 6 & $3 \%$ & marine + terr. & 2 & $15 \%$ & 3 & $2 \%$ & 1 & $3 \%$ \\
\hline & & & & Total & 6 & $46 \%$ & 73 & $48 \%$ & 20 & $54 \%$ \\
\hline
\end{tabular}

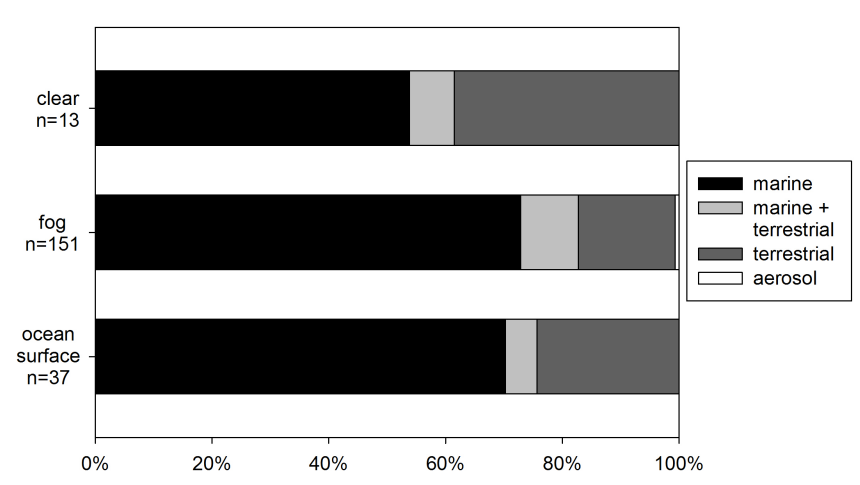

Fig. 5. Top hits source analysis for clear, fog, and ocean sequence libraries (coastal Maine, USA).

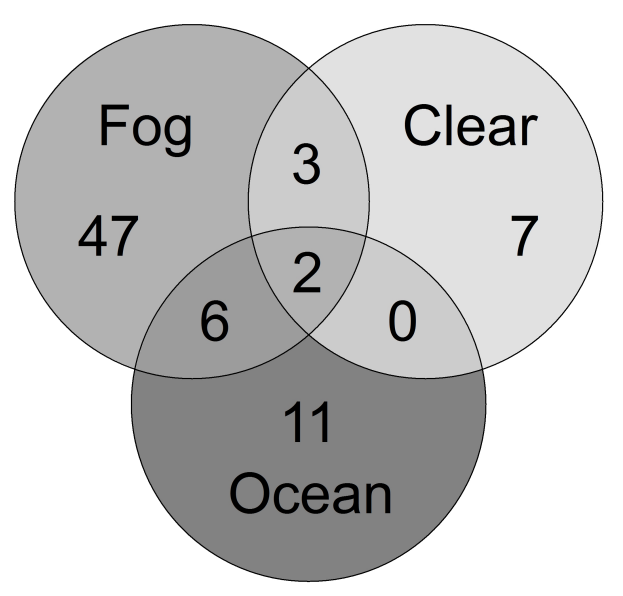

Fig. 6. Venn diagram constructed from MOTHUR OTU analysis of coastal aerosol (during foggy and clear conditions) and ocean sequence libraries (Maine, USA), using the average neighbor algorithm with $97 \%$ similarity cut-off.
Table 4. Results of similarity indices calculations comparing fog and clear libraries to the ocean library; samples collected from coastal Maine, USA. C.I. = confidence interval, Est. = estimated.

\begin{tabular}{lll}
\hline & Ocean-Fog & Ocean-Clear \\
\hline Shared OTU's & 8 & 2 \\
Shared OTU's (Chao Est.) & 11 & 3 \\
Jaccard (Chao Est.) & 0.519 & 0.085 \\
Jaccard 95\% C.I. & $0.809-0.229$ & $0.216--0.046$ \\
Sorenson (Chao Est.) & 0.683 & 0.157 \\
Sorenson 95\% C.I. & $0.979-0.387$ & $0.371--0.057$ \\
\hline
\end{tabular}

were closely matched with GenBank sequences originating in marine environments (Fig. 5). Third, the culturable microbial aerosol sequence library in both clear and foggy conditions shared dominant OTU's with the ocean surface sequence library (Fig. 6, Tables 2, 3). Fourth, on a taxonomic level, culturable microbial aerosols falling out at our site were more similar to those detected from a boat in coastal waters (Cho and Hwang, 2011) than those detected from a terrestrial-based tower further inland (Fahlgren et al., 2010); detected at greater sampling heights above the ocean surface (Urbano et al., 2011); or detected in montane cloud water (Amato et al., 2007) (Fig. 3).

As reported in Dueker et al. (2011), aerosol particle size and microbial fallout increase significantly under foggy conditions in this coastal environment. Here we demonstrate that aerosol particle size increased with increasing, but still low $\left(<2 \mathrm{~m} \mathrm{~s}^{-1}\right)$, wind speeds under foggy conditions (Fig. 1). Because onshore wind speeds $>3.0 \mathrm{~m} \mathrm{~s}^{-1}$ are required for new local large-particle production from the ocean surface (Lewis and Schwartz, 2004), this increase in mean aerosol particle size was most likely a product of reduced deposition 
of pre-existing large particles, allowing them to reach the particle counter before deposition. Low onshore winds may have either increased horizontal transport of large particles before settling and/or decreased large particle settling rates through turbulence and wind shear.

This interaction of low onshore winds and fog presence should result in primarily large, local aerosol particles depositing on plates when wind is present with fog, in contrast to a combination of local large and local small particles depositing under no-wind foggy conditions. The major taxonomic differences between no-wind and wind microbial fallout libraries was the significantly higher percentage of Vibrionales in the wind library and the higher percentage of Pseudomonadales (Psychrobacter sp.), Bacillales (Bacillus sp.) and Flavobacteria in the no-wind library. While we would expect that taxa would be randomly associated with particle size at the source or at the moment of aerosol formation, we can also expect a decrease in particle size with distance of transport. The no-wind library, then, may have had representation from both local marine (large and small particles) and remote marine/terrestrial sources (small particles), resulting in the increased frequency of "hardier" bacteria in the library (Bacillus sp. are spore-formers, Pseudomonadales and Flavobacteria are noted by Agogue et al. (2005) to have UV resistance). This hypothesis is further supported by the significant dominance of Pseudomonadales in Gammaproteobacteria libraries (Fig. 4) in Amato et al. (2007) and Fahlgren et al. (2010). Vibrionales, though common marine organisms, were absent in both Urbano et al.'s (2011) and Fahlgren et al.'s (2010) libraries but present in this study's library and that of Cho et al. (2011). The differences in representation may be due to differences in media selection, or increased sampling distances from water surfaces, since Urbano et al. (2011) sampled over $12 \mathrm{~m}$ above the water surface and Fahlgren et al. (2010) sampled $200 \mathrm{~m}$ from the shoreline. Vibrionales may no longer be culturable when they reach as far inland as Fahlgren et al.'s samplers (2010), or may be attached to aerosol particles that settle quickly and do not reach the heights ( $>12 \mathrm{~m}$ ) sampled by Urbano et al. (2011). The Pseudomonadales, however, may be hardier and/or attached to smaller particles that transfer farther before depositing.

The taxonomic comparison of previous coastal aerosol sequence libraries strongly suggests that Proteobacteria are the dominant phylum in coastal microbial aerosols (Fig. 3) regardless of microbial sampling method (culture-based - testing relative viability as in this study, or culture-independent - DNA extraction of viable and non-viable cells from filters). Also, the class Gammaproteobacteria represented large fractions of most sequence libraries (Fig. 4). Agogue et al. (2005) found that Gammaproteobacteria, specifically Pseudomonas sp. and Alteromonas sp., were highly resistant to solar radiation.

Within the Gammaproteobacteria, it is notable that both of Fahlgren et al.'s (2010) libraries are missing the orders Alteromonadales, Vibrionales and Oceanospirillales, whereas these orders are prevalent in both this study and Cho et al. (2011). The difference in these libraries may be due to the proximity of sampling sites to the ocean surface, allowing for closer sampling sites to capture a broader range of locallyproduced marine microbial aerosols attached to larger particles that settle out before being transported long-distances. Cho et al. (2011) sampled directly above ocean waters, allowing for the immediate capture of locally-produced microbial aerosols, whereas this study measured microbial aerosols $6-10 \mathrm{~m}$ inland. The prevalence of fog at this site may have allowed for increased survival time for these orders before depositing on exposed plates and suggests that these bacteria are more likely to be observed in locally produced aerosol particles that have not been exposed to the stressors associated with longer duration transport. However, the absence of these groups from the culture independent library of Fahlgren et al. (2010) indicates that these groups are missing from the aerosols and not simply inactivated through aerosolization stress (since molecular approaches applied to total aerosols should detect inactivated cells as well). Potential removal processes in the near-shore environment include rapid aerosol particle settling rates through gravitational settling. Gravitational settling of aerosol particles is known to be modulated by winds, rain and fog (Seinfeld, 2006; Gultepe et al., 2007; Dueker et al., 2011). These influences should produce detectable changes in microbial aerosol community membership and structure, given differing residence times and transport distances of aerosol particles.

\subsection{Fog increases culturability of aerosolized marine microbes}

As reported in Dueker et al. (2011), fog presence/absence did not have a statistically significant effect on total microbial aerosol concentrations at this site, but culturable microbial fallout increased significantly with fog presence. These results support the interpretation of increased microbial fallout during fog events as an increase in the number of cells depositing and/or increased viability of cells depositing. Results from molecular analyses of the culturable depositing microbial aerosols provide further evidence that fog increases the viability, and not just gravitational settling rates, of marine microbial aerosols in the near-shore environment. OTU's dominant in the fog sequence library were marine in source and either were not present in or represented only small fractions of the clear sequence library (Table 3). Compared to the clear sequence library, the fog sequence library was more similar in structure to the ocean sequence library (Table 4). Also, the clear sequence library contained a large number of sequences attributed to "hardy" terrestrial bacteria, indicating a selection by clear conditions for microorganisms able to withstand stresses associated with aerosolization, most of which were absent from fog and ocean libraries. 
Earlier studies have reported increases in microbial aerosol viability with increased relative humidity (RH) (Griffiths and Decosemo, 1994). Fog should be considered the extreme end member of an RH effects curve. Fuzzi et al. (1997) found that microbial aerosol numbers increased by one to two orders of magnitude with the presence of fog in an inland valley, and was the first to speculate that fog droplets could serve as culture media for aerosolized bacteria, enabling these bacteria to survive aerosolization stresses, metabolize and reproduce.

If fog were merely increasing gravitational deposition of microbial aerosols, the fog sequence library from this study should be very similar to the clear library in structure. The very low microbial fallout rates encountered under clear conditions here (Fig. 2) resulted in a small library $(n=13)$, but this library should at any rate be a subset of the larger fog library $(n=151)$, with over-representation from the dominant OTU's found in the fog. However, that was not the case. Also, although the clear sequence library was dominated by marine bacteria (Fig. 5), the other sequences represented "hardy" terrestrial bacteria, including spore formers (Bacillus sp.), soil organisms (Burkholderia sp., Kocuria sp.) and other cosmopolitan bacteria (Serratia sp., Rhodococcus sp.), indicating a more remote source representation in this library.

The presence of fog, on the other hand, appeared to favor the culturability of certain groups often found in marine environments. The dominant class in the fog library was the Gammaproteobacteria, most notably the genera of Vibrio, Pseudomonadales and Psychrobacter (Table 2), which were overwhelmingly marine in the top hits source analysis. Also, the close resemblance of the fog library's source (Fig. 5) and significantly increased structural identity similarity (in contrast with the clear library) to the ocean library (Table 4) is strong evidence that fog enhanced the culturability, and therefore the viability, of local, marine-originated microbial aerosols, and that there was a strong coupling between ocean and fog microbial content. This finding is the first evidence of a difference in community composition and microbial viability associated with fog compared to clear aerosol conditions and strongly supports a dual role for fog (physical and biological) in increasing culturable microbial aerosol fallout.

\section{Conclusions}

This study connects patterns in the composition and deposition of microbial aerosols to physical environmental processes in a coastal environment. The data support the hypothesis that local production from the ocean surface dominates microbial aerosols in the near-shore environment. The data also strongly support the predictions made by earlier researchers that fog increases the viability of microbial aerosols, through both physical and biological processes.
Our research provides a strong case for ecologically relevant ocean-terrestrial transfer of microbes in the near-shore environment: fog and ocean are clearly microbially-coupled at the coast. Therefore, it appears that microbes in the coastal ocean surface dominate microbial aerosols in coastal fog. Other coastal surface water materials, including nutrients (Rinaldi et al., 2009), that are ejected along with these marine microbes should also be dominant in coastal fogs (Weathers et al., 2000). Our study showed that low winds moving this fog will increase the residence time, and therefore the inland transport, of larger colonized particles. Coastal fogs are known to move kilometers inland, which means that they have the potential to transport ocean nutrients and viable microbes to terrestrial systems seemingly isolated from the coastal environment (Weathers et al., 2000; Ewing et al., 2009). Implications of this transport include detectable feedbacks between terrestrial and coastal systems as a result of changes in land use and water use. Future research should be focused on the chemical, physical, and biological interaction of ocean, atmosphere, and land. Particular attention to the potential connection between water quality and air quality at coastal sites is also warranted.

\section{Supplementary material related to this article is available online at: http://www.biogeosciences.net/9/803/2012/ bg-9-803-2012-supplement.pdf.}

Acknowledgements. We thank Wade McGillis, Philip Orton, Jamie Stafford-Hill, Amanda Lindsey, Ilana Berger, Hannah Dueker, and the Berger family for assistance in both the field and the lab and Elinor Downs for study site access, shelter, and lab space in the field. Funding was provided by Columbia University (RISE and ADVANCE programs), NASA Ocean Biology and Biogeochemistry Program Grant NNG05GR37G to Ajit Subramaniam, the Wallace Foundation, and the Brinson Foundation. This is Lamont Doherty Earth Observatory contribution number 7523.

Edited by: K. Suzuki

\section{References}

Agogue, H., Joux, F., Obernosterer, I., and Lebaron, P.: Resistance of marine bacterioneuston to solar radiation, Appl. Environ. Microb., 71, 5282-5289, 2005.

Aller, J. Y., Kuznetsova, M. R., Jahns, C. J., and Kemp, P. F.: The sea surface microlayer as a source of viral and bacterial enrichment in marine aerosols, J. Aerosol. Sci., 36, 801-812, 2005.

Amato, P., Menager, M., Sancelme, M., Laj, P., Mailhot, G., and Delort, A. M.: Microbial population in cloud water at the Puy de Dome: Implications for the chemistry of clouds, Atmos. Environ., 39, 4143-4153, 2005.

Amato, P., Parazols, M., Sancelme, M., Laj, P., Mailhot, G., and Delort, A. M.: Microorganisms isolated from the water phase of tropospheric clouds at the Puy de Dome: major groups and 
growth abilities at low temperatures, FEMS Microbiol. Ecol., 59, 242-254, 2007.

Ariya, P. A., Nepotchatykh, O., Ignatova, O., and Amyot, M.: Microbiological degradation of atmospheric organic compounds, Geophys. Res. Lett., 29, 34:1-4, doi:10.1029/2002GL015637, 2002.

Ariya, P. A., Sun, J., Eltouny, N. A., Hudson, E. D., Hayes, C. T., and Kos, G.: Physical and chemical characterization of bioaerosols - Implications for nucleation processes, Int. Rev. Phys. Chem., 28, 1-32, 2009.

Bauer, H., Kasper-Giebl, A., Loflund, M., Giebl, H., Hitzenberger, R., Zibuschka, F., and Puxbaum, H.: The contribution of bacteria and fungal spores to the organic carbon content of cloud water, precipitation and aerosols, Atmos. Res., 64, 109-119, 2002.

Bauer, H., Giebl, H., Hitzenberger, R., Kasper-Giebl, A., Reischl, G., Zibuschka, F., and Puxbaum, H.: Airborne bacteria as cloud condensation nuclei, J. Geophys. Res.-Atmos., 108, 1-5, 2003.

Blanchard, D. C. and Syzdek, L.: Bubbles and Water-to Air Transfer of Bacteria, Bull. Amer. Meteorol. Soc., 52, 1136-1141, 1971.

Burrows, S. M., Butler, T., Jöckel, P., Tost, H., Kerkweg, A., Pöschl, U., and Lawrence, M. G.: Bacteria in the global atmosphere - Part 2: Modeling of emissions and transport between different ecosystems, Atmos. Chem. Phys., 9, 9281-9297, doi:10.5194/acp-9-9281-2009, 2009.

Castello, J. D., Lakshman, D. K., Tavantzis, S. M., Rogers, S. O., Bachand, G. D., Jagels, R., Carlisle, J., and Liu, Y.: Detection of Infectious Tomato Mosaic Tobamovirus in Fog and Clouds, Phytopathology, 85, 1409-1412, 1995.

Chao, A., Chazdon, R. L., Colwell, R. K., and Shen, T. J.: A new statistical approach for assessing similarity of species composition with incidence and abundance data, Ecol. Lett., 8, 148-159, 2005.

Cho, B. C. and Hwang, C. Y.: Prokaryotic abundance and $16 \mathrm{~S}$ rRNA gene sequences detected in marine aerosols on the East Sea (Korea), FEMS Microbiol. Ecol., 76, 327-341, 2011.

Cole, J. R., Wang, Q., Cardenas, E., Fish, J., Chai, B., Farris, R. J., Kulam-Syed-Mohideen, A. S., McGarrell, D. M., Marsh, T., Garrity, G. M., and Tiedje, J. M.: The Ribosomal Database Project: improved alignments and new tools for rRNA analysis, Nucleic Acids Research, 37, D141-D145, 2009.

Colwell, R. K.: EstimateS: Statistical estimation of species richness and shared species from samples, User's Guide and application published at: http://purl.oclc.org/estimates, 2009.

de Leeuw, G., Neele, F. P., Hill, M., Smith, M. H., and Vignali, E.: Production of sea spray aerosol in the surf zone, J. Geophys. Res.-Atmos., 105, 29397-29409, 2000.

Deguillaume, L., Leriche, M., Amato, P., Ariya, P. A., Delort, A.M., Pöschl, U., Chaumerliac, N., Bauer, H., Flossmann, A. I., and Morris, C. E.: Microbiology and atmospheric processes: chemical interactions of primary biological aerosols, Biogeosciences, 5, 1073-1084, doi:10.5194/bg-5-1073-2008, 2008.

Dimmick, R. L., Wolochow, H., and Chatigny, M. A.: Evidence for More Than One Division of Bacteria within Airborne Particles, Appl. Environ. Microb., 38, 642-643, 1979a.

Dimmick, R. L., Wolochow, H., and Chatigny, M. A.: Evidence That Bacteria Can Form New Cells in Airborne Particles, Appl. Environ. Microb., 37, 924-927, 1979b.

Drummond, A., Ashton, B., Buxton, S., Cheung, M., Cooper, A.,
Heled, J., Kearse, M., Moir, R., Stones-Havas, S., Sturrock, S., Thierer, T., and Wilson, A.: Geneious v5.1. Available from http: //www.geneious.com, 2010.

Dueker, M. E., Weathers, K. C., O’Mullan, G. D., Juhl, A. R., and Uriarte, M.: Environmental Controls on Coastal Coarse Aerosols: Implications for Microbial Content and Deposition in the Near-Shore Environment, Environ. Sci. Tech., 45, 33863392, 2011.

Ekström, S., Noziére, B., Hultberg, M., Alsberg, T., Magnèr, J., Nilsson, E. D., and Artaxo, P.: A possible role of ground-based microorganisms on cloud formation in the atmosphere, Biogeosciences, 7, 387-394, doi:10.5194/bg-7-387-2010, 2010.

Ewing, H. A., Weathers, K. C., Templer, P. H., Dawson, T. E., Firestone, M. K., Elliott, A. M., and Boukili, V. K. S.: Fog Water and Ecosystem Function: Heterogeneity in a California Redwood Forest, Ecosystems, 12, 417-433, 2009.

Fahlgren, C., Hagstrom, A., Nilsson, D., and Zweifel, U. L.: Annual Variations in the Diversity, Viability, and Origin of Airborne Bacteria, Appl. Environ. Microb., 76, 3015-3025, 2010.

Fitzgerald, J. W.: Marine Aerosols - A Review, Atmos. Environ. Part a-General Topics, 25, 533-545, 1991.

Fuzzi, S., Mandrioli, P., and Perfetto, A.: Fog droplets - An atmospheric source of secondary biological aerosol particles, Atmos. Environ., 31, 287-290, 1997.

Griffiths, W. D. and Decosemo, G. A. L.: The assessment of bioaerosols - A Critical Review, J. Aerosol. Sci., 25, 1425-1458, 1994.

Gultepe, I., Tardif, R., Michaelides, S. C., Cermak, J., Bott, A., Bendix, J., Muller, M. D., Pagowski, M., Hansen, B., Ellrod, G., Jacobs, W., Toth, G., and Cober, S. G.: Fog research: A review of past achievements and future perspectives, Pure Appl. Geophys., 164, 1121-1159, 2007.

Hamilton, W. D. and Lenton, T. M.: Spora and Gaia: How microbes fly with their clouds, Ethol. Ecol. Evol., 10, 1-16, 1998.

Kuznetsova, M., Lee, C., Aller, J., and Frew, N.: Enrichment of amino acids in the sea surface microlayer at coastal and open ocean sites in the North Atlantic Ocean, Limnol. Oceanogr., 49, 1605-1619, 2004.

Lewis, E. R. and Schwartz, S. E.: Sea salt aerosol production : mechanisms, methods, measurements and models : a critical review / Ernie R. Lewis, Stephen E. Schwartz, Geophysical Monographs, American Geophysical Union, Washington, D. C., 2004

Lighthart, B. and Shaffer, B. T.: Viable bacterial aerosol particle size distributions in the midsummer atmosphere at an isolated location in the high desert chaparral, Aerobiologia, 11, 19-25, 1995.

Marks, R., Kruczalak, K., Jankowska, K., and Michalska, M.: Bacteria and fungi in air over the Gulf of Gdansk and Baltic sea, J. Aerosol. Sci., 32, 237-250, 2001.

Posfai, M., Anderson, J. R., Buseck, P. R., and Sievering, H.: Compositional variations of sea-salt-mode aerosol-particles from the North-Atlantic, J. Geophys. Res.-Atmos., 100, 23063-23074, 1995.

Prospero, J. M., Blades, E., Mathison, G., and Naidu, R.: Interhemispheric transport of viable fungi and bacteria from Africa to the Caribbean with soil dust, Aerobiologia, 21, 1-19, 2005.

Rinaldi, M., Facchini, M. C., Decesari, S., Carbone, C., Finessi, E., Mircea, M., Fuzzi, S., Ceburnis, D., Ehn, M., Kulmala, M., de Leeuw, G., and O'Dowd, C. D.: On the representativeness of 
coastal aerosol studies to open ocean studies: Mace Head - a case study, Atmos. Chem. Phys., 9, 9635-9646, doi:10.5194/acp-99635-2009, 2009.

Schloss, P. D., Westcott, S. L., Ryabin, T., Hall, J. R., Hartmann, M., Hollister, E. B., Lesniewski, R. A., Oakley, B. B., Parks, D. H., Robinson, C. J., Sahl, J. W., Stres, B., Thallinger, G. G., Van Horn, D. J., and Weber, C. F.: Introducing mothur: OpenSource, Platform-Independent, Community-Supported Software for Describing and Comparing Microbial Communities, Appl. Environ. Microb., 75, 7537-7541, 2009.

Seinfeld, J. H. and Pandis, S. N.: Atmospheric chemistry and physics : from air pollution to climate change, 2 Edn., Wiley, Hoboken, N.J., 2006.

Shaffer, B. T. and Lighthart, B.: Survey of culturable airborne bacteria at four diverse locations in Oregon: Urban, rural, forest, and coastal, Microb. Ecol., 34, 167-177, 1997.

Teske, A., Hinrichs, K. U., Edgcomb, V., Gomez, A. D., Kysela, D., Sylva, S. P., Sogin, M. L., and Jannasch, H. W.: Microbial diversity of hydrothermal sediments in the Guaymas Basin: Evidence for anaerobic methanotrophic communities, Appl. Environ. Microb., 68, 1994-2007, 2002.

Tong, Y. Y. and Lighthart, B.: Solar radiation is shown to select for pigmented bacteria in the ambient outdoor atmosphere, Photochem. Photobiol., 65, 103-106, 1997.

Urbano, R., Palenik, B., Gaston, C. J., and Prather, K. A.: Detection and phylogenetic analysis of coastal bioaerosols using culture dependent and independent techniques, Biogeosciences, 8, 301-309, 2011,

http://www.biogeosciences.net/8/301/2011/.
Vaïtilingom, M., Charbouillot, T., Deguillaume, L., Maisonobe, R., Parazols, M., Amato, P., Sancelme, M., and Delort, A.-M.: Atmospheric chemistry of carboxylic acids: microbial implication versus photochemistry, Atmos. Chem. Phys., 11, 8721-8733, doi:10.5194/acp-11-8721-2011, 2011.

Vignati, E., de Leeuw, G., Schulz, M., and Plate, E.: Characterization of aerosols at a coastal site near Vindeby (Denmark), J. Geophys. Res.-Oceans, 104, 3277-3287, 1999.

Wang, Q., Garrity, G. M., Tiedje, J. M., and Cole, J. R.: Naive Bayesian classifier for rapid assignment of rRNA sequences into the new bacterial taxonomy, Appl. Environ. Microb., 73, 52615267, 2007.

Weathers, K. C., Likens, G. E., Bormann, F. H., Bicknell, S. H., Bormann, B. T., Daube, B. C., Eaton, J. S., Galloway, J. N., Keene, W. C., Kimball, K. D., McDowell, W. H., Siccama, T. G., Smiley, D., and Tarrant, R. A.: Cloudwater Chemistry from 10 Sites in North-America, Environ. Sci. Tech., 22, 1018-1026, 1988.

Weathers, K. C.: The importance of cloud and fog in the maintenance of ecosystems, Trends Ecol. Evol., 14, 214-215, 1999.

Weathers, K. C., Lovett, G. M., Likens, G. E., and Caraco, N. F. M.: Cloudwater inputs of nitrogen to forest ecosystems in southern Chile: Forms, fluxes, and sources, Ecosystems, 3, 590-595, 2000.

Woodcock, A. H.: Salt Nuclei in Marine Air as a Function of Altitude and Wind Force, J. Meteorol., 10, 362-371, 1953. 